\title{
The application of adlerian psychotherapy for an adult with high functioning autism and depression
}

\begin{abstract}
High functioning autism (HFA) in adults is often accompanied by depression disorder. However, relatively few reports have focused on the treatment of such cases. This report introduced the intervention of Adlerian therapy for an adult with HFA and depression, in order to provide some suggestions for other therapists. The client was a 51-year-old female servant who searched for counseling through the Center of Work Strengthening due to the appearance of psychosomatic complaints when dealing with her occupational accident. The counseling entailed 10 interventions, one day a week for more than two months, with 60-90minutes per intervention. The client not only exhibited symptoms of depression and anxiety, but also HFA. The therapist applied four stages, as suggested by Adlerian therapy, to the client with HFA:

1. Relationship-building: respecting HFA clients' subjective experience and listening carefully with empathy.

2. Assessment: asking questions about their history and the current functioning of their interpersonal relationships.

3. Interpretation and insights: discussing with the client and euphemistically pointing out the underlying motives for behaving the way she does in the 'here and now', to help her understand the limitations of the lifestyle she has chosen.

4. Reorientation and reeducation: to encourage clients to take the risk in engaging in new activities to adapt to the changes, and to adjust their rigid fictional final goals, and social interests. Finally, the client went back to work without serious depression and was able to express her negative emotions to her supervisor, as well as adjust her daily routine. Adults with HFA have low social interests and rigid beliefs which easily make them feel depressed when they suffer stress; their condition can be improved through Adlerian therapy.
\end{abstract}

Keywords: adlerian psychotherapy, autism spectrum disorder, counseling process, depression, high functioning autism
Volume 8 Issue 3 - 2017

\author{
Hom Yi Leel,2 \\ 'Department of Speech Language Pathology and Audiology, \\ Chung Shan Medical University, Taiwan? \\ ${ }^{2}$ Department of Pediatrics, Chung Shan Medical University \\ Hospital,Taiwan
}

\begin{abstract}
Correspondence: Hom-Yi Lee, Professor, Department of Speech Language Pathology and Audiology, Chung Shan Medical University No. I I0, Sec. I, Jianguo N. Rd., Taichung City 4020 I, Taiwan,Email homyilee@gmail.com
\end{abstract}

Received: September 25, 2017 | Published: November 07, 2017
Abbreviations: AS, asperger's syndrome; ASD, autism spectrum disorder; APA, american psychiatric association; HFA, high-functioning autism; SOP, standard operating procedures

\section{Introduction}

Autism spectrum disorders (ASD) are characterized by persistent impairment in social communications and interactions across multiple contexts, as well as restricted or repetitive patterns of behavior, interests, or activities, according to the fifth edition of the Diagnostic and Statistical Manual of Mental Disorders (DSM-V). ${ }^{1}$ The population of ASD has been increasing since the 1980s. Gillberg \& Wing ${ }^{2}$ reviewed researches between 1996 and 1997 and discovered that the population of ASD had increased from $0.0005 \%$ to $0.001 \%$. In recent years, the prevalence of ASDs had approached 1\%. ${ }^{1}$ In a recent large scale sampling, South Korea discovered that more than $2.6 \%$ of elementary school students have ASD. ${ }^{3}$ These findings indicate that ASD has increased significantly in a short time period. In addition, White et al., ${ }^{4}$ suggest that a significant proportion of adults in the community may have undiagnosed ASD. It is noteworthy that depression occurs more frequently with ASD patients than among normal people, with a prevalence rate between $10.1 \%$ and $53 \%$ across studies with different research methods. ${ }^{5,6}$ Some evidence has shown that behavioral therapy can probably reduce ASD depression among children, and that cognitive behavioral therapy is a common behavioral therapy. Researchers have shown that cognitive behavioral therapy may help sufferers adjust their coping strategies, maladaptive behaviors, and negative thoughts, while improving the inflexibility of their cognition. However, most cognitive behavioral therapy programs were originally designed for normal children, and then adjusted for ASD children. Also, most of these programs were especially tailored for those with anxiety, aggressive behaviors, and the common deficiencies of ASD, instead of depression. ${ }^{7}$ In addition, both children and adults with ASD often take psychotropic medication. In a large sample survey, $64 \%$ of children with ASD take at least one medication. ${ }^{8}$ Similarly, $70 \%$ of adolescents and adults with ASD take psychotropic or non-psychotropic medication, with the usage of psychotropic medication appearing to increase 4.5 years later ${ }^{9}$. On the other hand, those ASD patients with normal IQ, better language and cognitive capability, and exhibiting mild characteristics of ASD are considered 'high-functioning' (often diagnosed with high-functioning autism (HFA), or Asperger's syndrome (AS) in the past). Few adults with HFA have good employment or educational outcomes. ${ }^{10-12} \mathrm{Kim}$ et al., ${ }^{13}$ discovered that teenagers with HFA or AS are more susceptible to comorbid depression (17\%) and anxiety (14\%). These findings are similar to those of studies on children with ASD; greater rumination on one's perceived impairments and lower perceived social support have been associated with increased depressive symptoms for verbal adolescent- adult with ASD. ${ }^{14}$ As 
mentioned previously, it is expected that the need for psychological therapy for adults with ASD is increasing, especially because they readily experience comorbid depression and anxiety; however, there are few researches on psychological therapies for HFA adults. There are also few psychological therapy researches focusing on ASD adults or adults. One research confirmed that modified mindfulness-based therapy (MBT-AS) can reduce anxiety, depression and rumination of adults with HFA. MBT-AS encourages clients to recognize their relevant feelings and thoughts when they occur, and try to accept them. ${ }^{15}$

Wing ${ }^{16}$ suggests that well-structured and instructive psychodynamic therapy may be helpful to some ASD patients who have sufficient verbal ability. Chandrasekhar \& Sikich ${ }^{17}$ concluded that the efficacy of medication and psychological therapy intervention still need more research for confirmation. Therefore, this report explores the practicability of well-structured and instructive psychodynamic therapy on HFA adults with depression. Although Adlerian Psychotherapy was not established specifically for HFA patients, it can describe HFA patient's behaviors precisely with some key concepts. For instance, 'social interest' refers to an action line related to one's community feeling; it involves the individual's positive attitude toward other people. Adler equated social interest with a sense of identification and empathy with others: "to see with the eyes of another, to hear with the ears of another, to feel with the heart of another." Those with social interest naturally tend to interact better with others. Those who lack social interest cannot interact and cooperate with others. ${ }^{18}$ HFA patients usually lack empathy and show low social interest. Adlerian psychotherapy also emphasizes the appearance of 'fictional finalism': the result of genetic and environmental effects that comprise personal values, beliefs, attitudes, goals, interests, subjective awareness of reality, and so on. This report considers that HFA patients are likely to establish unhealthy "fictional finalism", resulting in maladaptive behavior, including poor lifestyle or inappropriate SOP. Therefore, the therapeutic goals of Adlerian psychotherapy, including knowing and creating one's lifestyle, finding the appropriate goals for achieving excellence, promoting social interest, and so on, is suitable for HFA clients. Adlerian therapists work with clients through four stages of counseling: relationship- building, assessment, interpretation and insight, and reorientation..$^{18}$ This report hypothesizes that these stages can also prove helpful to adult clients with HFA, as explained below:

Relationship-building: HFA patients have difficulty in building relationships with others, but once they connect with people, they will trust them very much and listen to their suggestions. Moreover, HFA patients often take the initiative to discuss their own subjective views and experiences; therefore, it might be suitable to apply Adlerian psychotherapy for them since this approach takes patients' subjective views seriously.

a. Assessment: ASD patients may readily establish their Standard Operating Procedures (SOP) and suffer maladaptation in their life because they have rigid subjective views and beliefs. At this stage, the therapists evaluate and analyze the impact of the clients' foundational errors on their real life, and ascertain the clients' psychodynamics, wrong goals and wrong assumptions.

b. Interpretation and insights: Because HFA patients are very selfcentered, it is difficult for them to introspect. They need others to give them feedback to help them achieve self- understanding. The third stage of the Adlerian counseling process is to encourage clients to introspect. By listening to the explanation of their therapist, clients may gain insights into the causes and effects of their own conduct. The therapist acts as a mirror to let clients see their life, and become conscious of their fictional finalisms.

c. Reorientation and reeducation: Re-educating inappropriate goals into achievable goals. HFA patients cannot face the current changes in their life, often as a result of their rigid beliefs or SOP failure. Therefore, they need to establish a new and applicable SOP by changing their rigid beliefs. The last stage of the counseling process is to redirect and persuade the clients to change their life goals, lifestyle and social interests.

\section{Case report}

Mrs. W is a 51-year-old general employee at a public institution. $\mathrm{W}$ lives with her husband and two daughters in a middle-class family. $\mathrm{W}$ looks gentle and has an innocent mind, but her sense of justice and integrity often result in conflicts with her colleagues. W lost her balance and fell off her motorcycle twice due to muscle relaxation caused by a sudden loss of consciousness three months and two years ago, respectively. The latest fall caused her left little finger to suffer a comminuted fracture. Her doctor suggested that she rest for three months; however, the institution asked her to go back to work after one-week of recovery. The supervisor A thought that $\mathrm{W}$ was finding excuses for her laziness, which made W feel angry and wronged because she thought she had worked so hard for the institution all the time. After experiencing these events, W lost her self-confidence, cried easily and wanted to commit suicide. $\mathrm{W}$ received a diagnosis of major depressive disorder and panic disorder. Furthermore, during counseling, W was diagnosed by her psychiatrist as suffering from an autism spectrum disorder, but with high-functioning autism.

\section{History}

$\mathrm{W}$ is an introverted person. She has been afraid of strangers since her childhood; as a result, she didn't have friends at school. $\mathrm{W}$ remembers that the neighbour boys liked to tease her on the way to school during elementary school. During junior high school, she studied really hard every day and always got first place in regular class. However, W was often bullied by her classmates. W worked at a local public institution after graduating from vocational high school. Her great work performance gained her supervisor's recognition, but her jealous co-workers blackmailed her. Later, she was transferred to the social welfare department; she then worked with the secretary for many years. However, a secretary shifted the blame on her by putting official documents that the secretary forgot to deal with on her table. Once again, $\mathrm{W}$ was transferred to another position at another public institution and is still not getting better at her current job. W still doesn't get along well with her colleagues at her current job. In addition, $\mathrm{W}$ suffers great pressure because she is asked to deal with many tasks which are complex and full of uncertainty. After W got married, W had a bad relationship with her sister-in-law. Her sisterlaw felt jealous of the relationship between $\mathrm{W}$ and her in-laws, and became sarcastic, which put W under great pressure. W doesn't have any friends except for her husband. Her husband said that W has an upright personality which makes her easily offend people. Furthermore, W stated that she has a different lifestyle from those of her neighbours, so she usually doesn't interact with them.

\section{Assessment}

Although there was no history of HFA on her referral, the therapist discovered that W has HFA characteristics, assessed her HFA symptoms and referred her to the senior psychiatrist. Later, the psychiatrist also agreed that W has HFA. W scored 41 out of 50 
on the Mandarin version of the Autism-spectrum Quotient ${ }^{19}$ used to screen adults for Asperger Syndrome and high- functioning autism, and suggested a cut-off score of 30 for Taiwanese adults. The detailed HFA characteristics of $\mathrm{W}$ can be seen in the counseling process below. Furthermore, she scored 54 on the Taiwanese Depressive Questionnaire, ${ }^{20}$ which recommended a cut-off score of 29 for seeking professional help for depression. At the end of counseling, W scored 38 on the Mandarin version of the Autism-spectrum Quotient, but scored 18 on the Taiwanese Depressive Questionnaire.

\section{Treatment}

The counseling was 10 interventions, one day a week for more than two months, with 60-90minutes per intervention. The following section describes how the therapist counselled W with an Adlerian approach.

\section{Relationship-building}

The goal of this stage is to establish a collaborative therapeutic relationship with the clients. It can be established by supporting and encouraging the clients to introspect regarding their resources and advantages. In addition, Adlerian psychotherapy takes clients' subjective experiences seriously; thus, therapists can listen carefully and with empathy to clients' subjective experiences and clarify the therapeutic goals. The conceptualization of the clients will be checked and revised in future consultations. Referrals recorded that $\mathrm{W}$ fell from her motorcycle on the way to work, which confirmed her need for medical leave, but her supervisor didn't permit her to take the suggested medical leave and asked her get back to work within a week. Thus, $\mathrm{W}$ presents a lot of negative emotions. The therapist asked W to explain the interactions with her supervisor. During the counseling process, the therapist listened with empathy and kept supporting and encouraging her to talk about it. W talked about her motorcycle accident and said that due to perennial rheumatoid arthritis, it was not easy to recover the comminuted fracture caused by the motorcycle accident, so she asked for a medical leave to rest for three months. However, her supervisor kept asking her to submit relevant documents and considered that she didn't want to go to work on purpose. Therapist: You think that you've been working very hard. However, you asked for your sick leave because you really couldn't go to work after the motorcycle accident, but your colleagues and supervisors thought that you were just acting which made you feel that you were really wronged. (W keeps nodding and wiping her tears.) Therefore, the therapist's initial case conceptualization was: 'W thinks that she takes her work seriously; however, after the motorcycle accident, her supervisor considered that she didn't want to go to work on purpose and refused to permit her medical leave application, making her feel wronged. In addition, after two consecutive accidents, she has become even more helpless and lacking in self-confidence. She exhibits symptoms of panic disorder and depression. When her melancholy emerged, she cried easily and wanted to commit suicide.' After several consultations, $\mathrm{W}$ said that beside the bad relationship with her supervisor, her relationships with her colleagues and sister-in-law are not good either. W said that after she graduated from vocational high school, she became a worker at a local public institution. Her great performance at work gained her supervisor's recognition; therefore, she was transferred to the central public institutions. However, W recalled that 'When I was transferred, my colleagues wrote letters to intimidate me because they were jealous.' The therapist was respectful toward W and said: 'At that time, you must have been a very serious staff member.'
After working for several years, she left the institution and transferred to her current institution because one of her colleague shifted the blame onto her. W now serves as an inventory manager whose job is diverse and uncertain, which makes her feel incapable. Her biggest challenge is to manage the ins and outs of everyone's fixed assets. W said that 'People often transfer without clearly handing over the assets. They often say that other colleagues borrowed the asset from them or the asset didn't exist from the beginning.' This kind of uncontrollable job puts her under great pressure and makes her feel helpless. Furthermore, W said, 'These works should all be done by my colleague B. Why am I doing all of these?' She thinks that although B is about to retire, he shouldn't fool around. There is one other thing; $\mathrm{W}$ reported $\mathrm{B}$ for taking a box of color pens without permission. W emphasized that 'In the end, B retired without returning the pens and being punished. That was not fair.' We can notice that W has a strong sense of justice, but a lack of compassion, which is the reason why she has had bad relationships with her colleagues. When we look back on G's working experience, we also find that more complex and frequent social interactions in the workplace were needed, so it became more difficult for $\mathrm{W}$ to adapt to the environment. When the therapist listened carefully and gave $\mathrm{W}$ respectful feedback, W expressed more related events and poured out her feelings. In terms of family life, W has had a bad relationship with her sister-in-law because $\mathrm{W}$ got along with her in-laws better than she did. Her sister-in-law became jealous and was sarcastic to $\mathrm{G}$, which put $\mathrm{W}$ under great pressure. In this stage, the therapist revised the conceptualization of $\mathrm{G}$, and supposed that the emotional disturbance that $\mathrm{W}$ suffered from might be related to her interpersonal skills.

\section{Assessment}

The goal of this stage is to analyze the impact of clients' personality on their real life by assessing their family constellation, early recollections, and lifestyle, as well as identifying their fundamental errors. Subjective interviews can be carried out by asking clients to talk about their life story, including memories of the past major events and their feelings and thoughts associated with key incidents. This stage can help them understand how they see themselves and the world, so as to help them understand their lifestyle and life goals. Based on the renewed conceptualization that G's emotional distress is related to her interpersonal skills, the therapist ask about her relationships with classmates at school, and she said that she didn't have any friends at school. Agitated, she said that she had been bullied in her junior high school and elementary school. W remembered that the neighbour boys liked to tease her on the way to elementary school. During junior high school, W wasn't good enough at studying to get the chance to enter an elite class, she still studied really hard to be at the top in her regular class. However, she said that during lunch break, her classmates would read out her weekly notes to everyone, and laughed at the content she wrote. 'I pretended I was taking a nap, but I heard everything. I felt really sad,' she said. W doesn't have many friends except her husband now. Her husband said that she is straightforward with others which often make the situation appear cold. 'I broke up with some of my friends for her because I don't know when she will say something inappropriate to others. For example, she could not tolerate my friends smoking when dining. She told my friends directly that it is unhygienic to eat without using serving utensils; this made everyone feel awkward.' W doesn't like to interact with her neighbors either because she thinks her lifestyle is so different from theirs. It is obvious that $\mathrm{W}$ has difficulty in interacting with people, no matter whether in school, her workplace or on social occasions. W also said, 'I have been afraid of strangers since I was young.' Thus, we can 
infer that her social distress appeared during the early stage of her life. Moreover, W thinks that her unsuccessful social life is caused solely by others because she is kind and intelligent, while others like to make fun of her, thus, making her feel wronged. These show that $\mathrm{W}$ is a selfcentered person who only judges things according to her point of view, which is a characteristic of ASD; this is also the reason why patients with ASD have difficulty in interacting with others. In addition, some children with ASD may have delayed speech, and W recalled that she didn't start talking until she was three. In order to express that she works really hard, $\mathrm{W}$ emphasized that she needs to work according to her own SOP; otherwise, she may feel uncomfortable. For instance, she cleans her seat, waters her potted plants before she starts to work, and cleans her seat before she gets off work every day. Also, she used to clean her house every day, but after she suffered from rheumatoid arthritis, she couldn't do it too often, so she asked her husband to assist her, but he couldn't do it the way she wanted. For example, she used to tell him to clean the toilet cover after he peed, but he never did, so she would wait at the outside the lavatory, and cleaned the toilet cover after her husband finish peeing. Thus, we can consider that $\mathrm{W}$ takes her SOP really seriously. In addition, W doesn't like watching TV. She likes to live a simple life, enjoys having a cup of coffee and reading books alone at home during weekends. In particular, she likes to write down her dreams and hopes that someone can invent a mobile application to record dreams because sometimes she cannot record her dreams completely. It can clearly be seen that $\mathrm{W}$ has shown repetitive behaviors and interests. Thus, the therapist suggested that she discuss her HFA characteristics with the psychiatrist. As a result, the therapist corrected G's conceptualization once again, and considered that her HFA characteristics are the causes of her rigid beliefs and lifestyle, thus causing her social impairment and emotional distress. She insists on following the rules, like using serving utensils when dining, no smoking in public, public servants should not be corrupt; every task should follow her SOP, and so on. If something doesn't work precisely as she wants it to, like her colleagues not following the rules to transfer assets or her supervisor not following the labor legislation to permit her sick leave application, she feels uncomfortable and angry. She seems to display the 'fundamental error' that social norms should all be strictly followed without exception. After the motorcycle accident, she couldn't control others and her environment as she expected. In the end, she exhibited anxiety, depression, and so on.

\section{Interpretation and insight}

The goal in this stage is to promote clients' realization of their fictional final goals and frustrating behaviors to help them obtain insights after analyzing their ways of communicating, patterns of behavior, symptoms, social interactions, and so on. In addition, Adlerian interpretations are suggestions presented tentatively and indirectly in the form of open-ended questions. Thus, the therapist gave W some feedback about her HFA characteristics according to the assessment stage and asked tentative questions. Part of the dialogue is as follows:

When the therapist gave her some feedback about the interactions between her and her husband's family, W responded with nodding and crying most of the time.

Therapist: Are you the most obedient daughter-in-law in your husband's family?

G: Yes.

Therapist: Do you notice that you are always the most obedient student, daughter-in-law, and employee? Did you always want to be the best in front of the elderly?
G: We should be obedient to the elderly because we are younger. It is our duty.

Therapist: Could it be that you followed everything your teachers said since your childhood, so that you would always receive their praise?

\section{G: Yes. I was a good student at school.}

Therapist: After you started working, you followed your supervisors' orders, so you got promoted. After you got married, you followed everything your in-laws said. Thus, you really obey the elderly. However, is it possible that your feeling frustrated and sad now is related to your obedience?

\section{G: Why?}

Therapist: You think you work really hard for the institution and follow all the orders; however, this time, your supervisor didn't praise you, and instead he thinks that you are finding excuses for being lazy, which makes you feel frustrated, sad and even angry. At the same time, you are anxious because you think you could no longer receive praise from your supervisor. You really want to earn recognition from your supervisor. That is your problem.

W realizes the implications and laughs. She said: I don't want to follow the orders and I want to make my supervisors mad (W was joking; she looked very relieved.)

Thus, $\mathrm{W}$ realized that one of her fundamental errors was thinking that everyone needs to be obedient to earn recognition in any situation.

On the other hand, W reveals a fundamental error, that social norms need to be strictly followed, which results in her feeling uncomfortable when others break the rules.

Therapist: You care about rules and demand that others should follow the rules the same as you do. For instance, you think public servants should obey the guidelines of property encroachment law, including avoiding encroachment on public property, thus you reported your colleague B for his encroachment concerning the pens. However, your supervisor didn't punish him, which made you feel indignant. (W nods her head.)

\section{Reorientation and reeducation}

The goal of this stage is to persuade clients to change their fictional final goals, lifestyle, and social interests. It can be accomplished by discussing practicable solutions with clients, and encouraging them to try new things that they've never tried before. At this stage, the therapist discussed with $\mathrm{W}$ how to reduce her emotional distress. To change G's fictional final goal: 'To please the supervisor and receive appreciation and recognition for being obedient', the therapist encouraged her to express her needs and feelings, like being wronged or unsatisfied, and to communicate with her supervisors to avoid accumulating pressure. Being a successful employee does not mean that you will have to follow all instructions of the elderly. Doing the job well reflects a successful employee. Before she went back to work, she worried that her supervisor wouldn't adjust her work as. As expected, her supervisor didn't adjust her work schedule, which made her feel frustrated; thus, the therapist encouraged her to express her needs to her supervisor. After she expressed her needs, she got permission from her supervisor. She said that she started to express her feelings after she came for counseling. Moreover, the therapist suggested that she do some muscle relaxing activities and turn her attention away from the stressor in order to deal with her negative feelings and avoid being sent to the hospital again because 
of panic attacks. She said that she would walk out of her office and walk around the building. In the middle of and during the last part of the counseling, she didn't appear to panic any longer. Furthermore, she holds a fundamental error that social norms need to be strictly followed, which results in her feeling uncomfortable when others do not obey the rules. The therapist encouraged $\mathrm{W}$ to judge others with flexible standards in order to become more relieved.

Therapist: People can't meet the standards all the time. For example, if your teacher sets 90 points for passing criteria while in school. Can you always get 90 or more in every test? G: I usually got 90 or more when I was in junior high school, but I got 80 or more when I was in vocational high school because it's more difficult. The therapist used this case to educate $\mathrm{W}$ that standards may change due to different situations, and that sometimes we can't meet the standard under special conditions, but also that this is forgivable. As for developing social interests, the therapist encouraged $\mathrm{W}$ to chat with her colleagues at first, but it seemed to be hard for her to find friends in the workplace. She then started to share her experiences with a familiar street vendor, and the vendor also shared her experiences of having suffered from depression before. The vendor said, 'I needed to take care of my in-laws and my husband's older brother with mental retardation at that time, and I finally got through it.' W felt better after she listened to what the vendor said. During the middle stage of counseling, a 40- year-old colleague, the one who showed concern for her at the time she appeared to panic after she got back to work, shared with her the happiness of getting married; chatting made her feel good. At the later stage of counseling, W contacted two of her old friends. Although they have different religions, they both hoped that W could forgive her supervisor A. Her Christian friend told her to pray for her, and her Buddhist friend told her to chant for her; by doing so, her supervisor would get good karma and enjoy benevolent thoughts. $\mathrm{W}$ then started to question whether she should forgive A. She said that if A permitted her to take her sick leave, she would forgive her. The therapist encouraged her to forgive A unconditionally. 'You forgave someone before; you can do it this time.' W replied: 'Yes, I did. I forgave colleague B.' It is clear that increasing social interactions could help W comprehend the universality of her situation, gain new viewpoints, find solutions to her problems, make her more openminded and relieve her distress.

On the other hand, the therapist encouraged $\mathrm{W}$ to engage in some relaxing activities. At the late stage of counseling, W said that she had started drawing and that it made her happy. Her husband said that she used to draw when she was young. G's symptoms of anxiety and depression were reduced a lot; she no longer entertained the idea of suicide.

\section{Discussion}

As we see from the above, the main concepts of Adlerian psychotherapy are suitable for treating individuals with HFA who suffer from emotional distress because the common symptoms of HFA patients are low social interest and lack of empathy, which make them easily feel frustrated when they face challenges. However, Adlerian psychotherapy emphasizes social interest, including showing concern and empathy for others, and encourages clients increase their social interactions to help them find universality, new solutions to problems, and so on, in order to decrease the negative emotions. In this case, $\mathrm{W}$ found universality after she talked to the vendor and realized that she wasn't the most miserable person. Moreover, by connecting with her old friends, she realized that only when she forgave others could they change. No wonder, Sherman \& Dinkmeyer ${ }^{21}$ stated that how much we can share with, and be concerned about, others is an indicator of our mental health. In addition, Adlerian psychotherapy also emphasizes that people building their lifestyle based on the fictional final goals is caused by fundamental errors. Individuals with HFA often set up rigid fictional final goals due to their fundamental errors, and subsequently suffer from emotional maladaptation. G's fundamental errors included the belief that people should obey the elderly; employees should obey their supervisors, and so on. As we can see, one of her fictional final goals was 'Being obedient, to please the supervisor and receive appreciation and recognition.' However, her goal became hard to achieve after the motorcycle accident. As a result, the therapist encouraged her to realize her goals, express her feelings, and communicate with others. Furthermore, the fourstage approach of Adlerian psychotherapy can help depressed clients with HFA to get through their emotional distress. The four stages are outlined below:

Relationship-building: patients can trust therapists who respect HFA clients' subjective experiences and listen carefully with empathy. After the clients feel accepted, they will disclose more detailed information on what brought them to counseling.

Assessment: by asking questions about their history and the current functioning of interpersonal relationships, therapists can analyze the impact of fundamental errors on the HFA clients' life.

Interpretation and insights: therapists discuss open-ended questions with clients and explain their behaviors, to encourage them to obtain insights on their own HFA characteristics, behaviors, and the meanings behind their social interactions, thereby helping them gain awareness about the unspoken rules and values that are impacting their mood.

Reorientation and reeducation: therapists encourage clients to change their rigid fictional final goals, lifestyle, and social interests caused by HFA and to establish new goals and lifestyles to adapt to the changes. It is worth mentioning that during the interpretation and insight stage, although the therapist conducted open questions to encourage the client with HFA to get insights into the present problems, but what the therapist needs to explain will be more than what the client can become aware of solely by himself/herself.

\section{Conclusion}

This report finds that individuals with HFA easily experience depression or anxiety due to their religious beliefs, and suggests that the main concepts and four-stage approach of Adlerian psychotherapy can help depressed clients with HFA get through their emotional distress. Thus, well-structured and instructive psychodynamic psychotherapy may be helpful for individuals with HFA; that is, this case supports Wing's (16) point of view.

\section{Acknowledgements}

The author would like to thank Hui-Ching Hsu for her assistance with the English translation.

\section{Conflict of interest}

The author declares no potential conflicts of interest with respect to the research, authorship, and/or publication of this article

\section{Funding}

None.

\section{References}

1. American Psychiatric Association. Diagnostic and statistical manual of mental disorders (5th edn). Arlington, American Psychiatric Publishing, USA. 2013. 
2. Gillberg C, Wing L. Autism: Not an extremely rare disorder. Acta Psychiatrica Scand. 1999;(6):399-406.

3. Kim YS, Leventhal BL, Koh YJ, et al. Prevalence of autism spectrum disorders in a total population sample. Am J Psychiatry. 2011;168(9):904-912.

4. White S, Ollendick T, Bray B. College students on the autism spectrum. Autism. 2011;15(6):683-701.

5. Henry CA, Nowinski L, Koesterer K, et al. Low rates of depressed mood and depression diagnoses in a clinic review of children and adolescents with autistic disorder. Journal of Child and Adolescent Psychopharmacology. 2014;24:403-406.

6. Rosenberg RE, Kaufmann WE, Law J K, et al. Parent report of community psychiatric comorbid diagnoses in autism spectrum disorders. Autism Research and Treatment. 2011; 405849.

7. Danial JT, Wood JJ. Cognitive behavioral therapy for children with autism: review and considerations for future research. J Dev Behav Pediatr. 2013;34(9):702-715.

8. Spencer D, Marshall J, Post B, et al. Psychotropic medication use and polypharmacy in children with autism spectrum disorders. Pediatrics. 2013;132:833-840.

9. Esbensen AJ, Greenberg JS, Sletzer MM, et al. A longitudinal investigation of psychotropic and non-psychotropic medication use among adolescents and adults with autism spectrum disorders. J Autism Dev Disord. 2009;39(9):1339-1349.

10. Farley M, McMahon W, Fombonne E, et al. Twenty-year outcome for individuals with autism and average or near-average cognitive abilities. Autism Res. 2009;2(2):109-118.

11. Magiati I, Tay X, Howlin P. Cognitive, language, social and behavioural outcomes in adults with autism spectrum disorders: A systematic review of longitudinal follow-up studies in adulthood. Clin Psychol Rev. 2014;34(1):73-86.
12. Seltzer M, Shattuck P, Abbeduto L, et al. Trajectory of development in adolescents and adults with autism. Ment Retard Dev Disabil Res Rev. 2004;10(4):234-247.

13. Kim JA, Szatmari P, Bryson SE, et al. The prevalence of anxiety and mood problems among children with autism and Asperger syndrome. Autism. 2000;4(2):117-132.

14. Gotham K, Bishop SL, Brunwasser S, et al. Rumination and perceived impairment associated with depressive symptoms in a verbal adolescentadult ASD sample. Autism Res. 2014;7(3):381-391.

15. Spek AA, van Ham NC, Nyklícek I. Mindfulness-based therapy in adults with an autism spectrum disorder: a randomized controlled trial. Res Dev Disabil. 2013;34(1):246-253.

16. Wing L. Social and interpersonal needs. In: Schopler E \& Mesibov G (Eds.), Autism in Adolescents and Adults.. New Plenum International Sales Corporation, USA. 1983. p. 337-353.

17. Chandrasekhar T, Sikich L. Challenges in the Diagnosis and Treatment of Depression in Autism Spectrum Disorders Across the Lifespan. Dialogues Clin Neurosci. 2015;17(2):219-227.

18. Corey G. Theory and practice of counseling and psychotherapy. (8th edn), Australia Thomson/Brooks/Cole 2009, Australia. 2009. p.1-519.

19. Liu MJ. Screening Adults for Asperger Syndrome and High-Functioning Autism by Using the Autism-Spectrum Quotient (AQ) (Mandarin Version). Bulletin of Special Education. 2008;33(1):73-92.

20. Lee Y, Yang MJ, Lai TJ, et al. Development of the Taiwanese depression questionnaire. Chang Gung Med J. 2000;23(11):688-694.

21. Sherman R, Dinkmeyer D. Systems of family therapy: An Adlerian integration. Brunner/Mazel, USA. 1987. 